\title{
STATE LEGAL POLICY OF SCIENTIFIC PREDICTION
}

\section{Oleksandr Korystin ${ }^{1}$}

${ }^{I}$ Doctor of Science (Law), professor, chief Research Scientist of the Criminological Research Laboratory of the State Scientific Research Institute of the Ministry of Internal Affairs of Ukraine, Kyiv, Ukraine, e-mail: alex@korystin.pro,ORCID: https://orcid.org/0000-0001-9056-5475

Politics as a phenomenon covers almost all spheres of public life. Its content, principles, and values significantly affect the development of society. But, in turn, there is a reverse order, as politics is determined by socio-cultural and geopolitical features and largely depends on the subjects of political relations, especially in times of social transformation.

Many scientists' studies of transformation processes focus on the possible formation of the capacity to manage public relations which aren't dominated on objective but they do on subjective factors in the implementation of public policy. Analyzing the socio-political events in Ukraine in the period from 2004 to 2007, Yu. Shemshuchenko, O. Yushchyk pays attention to dominating "political expediency" in the implementation of public policy as a derivative of the process of confrontation of various political forces for power [1,6-8]. Scholars note that this determines the content of the political process in Ukraine. At the same time, politics is associated exclusively with the specific practical activities of the subjects of political relations. The scientific and intellectual component of the axiological characteristics of politics as the art of management in the sphere of socio-political life is lost.

That is why there is an urgent need to disclose and substantiate the scientific idea of politics, understanding the essence of this phenomenon, knowledge of its social nature, which will strengthen the influence of objective factors on politics, starting with key concepts, in particular, "politics of mind" and strategic political thinking based on forecasting socio-political processes and consequences.

The politics of reason. The whole history of mankind, the whole history of its intellectual growth is permeated by a dilemma: is the future predictable or uncertain. Many famous scientists were enlightened by the idea that the future is incomprehensible. The philosopher Sir Carl Popper [2] was distinguished by the originality of the fact that the world is fundamentally, relentlessly, and unjustifiably unpredictable. Developing this idea, Nasim Nicholas Taleb [3] emphasizes that our success in modeling (and forecasting) the world is offset by the increasing complexity of this world, and the role of the unpredictable is growing.

But can a person give up predicting the future? Despite the above, homo sapiens differ in that the whole history of mankind is trying to comprehend the future with the mind, raise the curtain, and look into the future, at least soon. In this regard, Plato [4] 
noted that man always seeks to penetrate the eyes of the mind into the future. And Daniel Denet [5], highlighting the most main ability of the brain, to make assumptions about the future and play out alternative scenarios, as well as that our brain is a "prognostic mechanism."

The genesis of such an effort is successfully illustrated by a certain sequence. From the early forms of human mastery of the future - mythology, prediction of the future, which was associated with the minds and activities of people, not supernatural forces - utopia, future-oriented human potential - science fiction, to scientific forecasting and development of a particular area - the science of the future futurology.

In turn, scientific and technological progress has finally established the validity of the need for scientific forecasting, are evidenced by many examples of successful prediction of future processes, among which it is enough to highlight, at least, the idea of the noosphere, formulated by Academician Vladimir Vernadsky [6, 159]. according to which the evolution of all living things takes place in the direction from less intelligent to more intelligent forms of life, mental development in itself is the meaning of human life.

In our opinion, the most important conclusions of the noosphere idea concern, first of all, the social system of society, a certain type of political system (nomocracy), based on the application of reason policy based on the priority of human reason: power belongs to those who know more and make fewer mistakes, which are checked by the quality of decision-making.

Highlighting the priority of the human mind, it is important to understand that the greater number of people who are aware of the key role of the mind, the better the decision-making of each person. Even Descartes [7] defined the mind as a logical conclusion from explicitly formulated references. With knowledge, you can make enough right decisions. In particular, knowing human nature, it is possible to improve social relations indefinitely or to create any political system.

At the same time, no person knows and cannot know most of the specific facts that determine the activities of the whole social system of society. And although at first glance it may seem that this is such a non-controversial issue that is in no way needs explanation and special evidence. But there is always a risk of forgetfulness because the knowledge which is fare possessed by an individual makes it extremely difficult to try to explain and wisely influence the processes taking place in society, which in turn severely limits their ability to identify and target them.

In a way, we can say that most of the social rules of conduct that guide our actions are nothing more than a form of adaptation to the inability of one person to consciously take into account all the specific facts that together form the social system. The use of a huge amount of knowledge, which can't be possessed by any 
single person, as a result of which all operate within a coherent structure, most of the constructive factors of which the individual consciousness is unknown, is a hallmark of advanced civilizations.

To ensure the greatest efficiency of the mind, it is necessary to recognize that the possibilities of the conscious mind are limited and that there is a need for other processes, namely abstract concepts that help to perceive the complexity of the concrete, which the human mind can't fully grasp.

An abstraction is an indispensable tool that allows the mind to perceive a reality that cannot be fully known. This is because abstraction is a characteristic of all the processes that define activity long before it is embodied in conscious thoughts or words. Whenever a situation arouses an individual's propensity for a particular pattern of reaction, there is a basic phenomenon called abstraction.

Thus, abstraction is not only a quality that is in some way characteristic of all mental processes but also the basis of a person's ability to navigate the world, which is only partially clear, which allows him to adapt to ignorance of most specific facts of his environment. In this case, the main emphasis of the rules that guide human activity is the central role of the abstract nature of all mental processes. In this sense, abstraction is not something that the mind deduces from the perception of reality, but rather a property of the categories by which it operates. Abstraction is not a product of the mind, but that what makes up the mind. We are not allowed to act with full knowledge of all the facts that characterize the situation; we have to highlight only certain essential aspects, and we do so not as a result of conscious and thoughtful choice, but using a mechanism which is controlled by our consciousness.

The illusion that the mind itself can tell us what to do, and therefore all intelligent people can and should unite around a common goal as members of a community, is quickly dispelled in an attempt to put it into practice. At the same time, however, the desire to use our mind to transform the whole society into a single, rational system does not disappear.

The use of abstractions expands the range of phenomena that our intellect can subjugate, but this is achieved only by limiting the ability to predict the consequences of our activities, in particular, and by the fact that we can adapt the world to our desires only in general terms. It is for this reason that liberalism limits the regulation of the general order in society by the establishment of such rules as are necessary for the formation of a certain minimum order, the so-called spontaneous order, the details of which we are not allowed to foresee. Thus, democratic society as the foundation of modern civilization is the result of man's growing ability to convey abstract thoughts, and when we say that common to the politics of the minds of political elites is their minds, we mean the ability to think abstractly. 
In the development of the analysis of the characteristic components of the politics of reason, modern political practice shows the dependence of the effectiveness and efficiency of planning and management on the level of forecasting future socio-political processes, which, in particular, is a pronounced component.

In the second half of the twentieth century thorough futurological ideas of the development of civilizations appeared in the scientific literature. In particular, the concept of post-industrial society by Alvin Toffler [8] is noteworthy, in which he noted that human mental abilities are an inexhaustible form of capital and in the coming decades the priority will be knowledge, and the information obtained through them will become the main form of ownership. According to his forecast, political life will acquire new characteristics in the future: information technologies will contribute to the creation of a new organizational anti-bureaucratic structure in the future.

The policy of scientific foresight. Francis Fukuyama [9], a well-known American futurist and professor of political science, predicts in The End of History and the Last Man (1992) that the evolutionary goal of modern society is democratic capitalism as an unalterable model of the political and economic organization not only in the West but also in aspiring societies. to be realized in the confrontation for human dignity.

The prediction of socio-political processes covers the theory, methodology, and practice of studying the dynamics and prospects of the development of various processes and phenomena. And the level of such research depends on the understanding of the whole spectrum of forms of socio-political life, the peculiarities of the functioning of political institutions and mechanisms, geopolitical institutions.

In the '80s of the twentieth century a new sociological theory of modern society (Ulrich Beck) [10], was appeared according to which, in the last third of the twentieth century human civilization has entered a new phase of its development - the phase of risk. Industrial society was characterized by the distribution of civilizational benefits, and its evolution was accompanied by the emergence of new factors to improve human life. In turn, the post-industrial society - a society of risk, is characterized primarily by the distribution of threats of different origins and their risks, the emergence of increasingly negative factors that accumulate and are unevenly distributed among members of society. It is the distribution of risks that becomes the main component of civilizational security.

The development of society in all historical times, one way or another, was characterized by a risky nature, but a deep awareness of the riskiness of human activity is a relatively late product of the development of scientific thought and everyday consciousness. Therefore, for most politicians, as well as for ordinary citizens, it is psychologically difficult to perceive the attribution of risk. 
W. Beck [10] believes that the risk society is formed not so much as a national but as a global society. Risks are characterized by the global nature of the spread, intangibility, remoteness, invisibility, uncertainty, irrationality, uncertainty, and complexity of insurance. He especially emphasizes that the political stability of risk society is characterized by stability only in the refusal to be aware of the consequences. Therefore, in his works, he constantly emphasizes the need to understand the risky nature of modern social development at the level of society and government.

Revealing the meaning of the term "risk", first of all, it should be noted its complexity and poly science. The general scientific principles of this concept were developed in sociology, economics, applied mathematics, psychology, deviantology, and so on. In recent years, risk research has become widespread in the legal and political sciences.

The concept of risk as a cultural neoplasm originated in the seventeenth century in connection with gambling, describing the probability of an event combined with the number of losses and gains. Since then, the calculation of the probability of risk has taken deep roots in the science and practice of social production, based on the mathematical theory of probability. However, in political practice, the concept of risk began to go beyond the context of probabilistic thinking and lose its primary connection with the probability parameter. The construct of risk, which has usually become quite common in political debates, has little to do with odds. However, it is a complex combination of determining the content of a particular threat and assessing its scale, probability, and absolute or relative value of the occurrence or failure of the event.

Risk in the context of socio-political activity is useful because it forms the basic scientific principles based on the model of the information society, taking into account the theory of security in the post-industrial state. The implementation of public policy has always been a difficult task and has always been associated with a greater or lesser degree of risk. The risk was, at least, that the outlined policy of the state could be either not implemented at all or only partially implemented.

Another option for risk in this case may be defrmed, distorted, distorted implementation to life of the political course. The implementation of policy can give results that are the opposite of those which conceived by its developers, bring harm instead of benefit, provoke the complication of social problems instead of solving them. It also happens that the fully implemented idea of the political leadership as its side or delayed consequences of the second, third, or even more distant order creates even more complex problems than the one that has been successfully solved. There are many examples to illustrate each of these options for implementing public policy; their large number both in history and in the present. 
The inertia of this point of view is not overcome today. Failures in the implementation of the policy by public opinion rely entirely on its developers, and even more often - on the executors. However, the assumption of a risky nature of the implementation of public policy can also serve as a basis for speculation aimed at covering up real dishonesty and incompetence. Therefore, an important scientific and practical problem is the identification of risk in the implementation of public policy and its separation from other causes of non-implementation of public administration decisions, including the above-mentioned errors, irresponsibility, and unprofessionalism. In order to do this, in turn, should seek clarification of the definition of "risk".

Risk is associated with the activities of management entities in a situation of uncertainty, with the dynamics of the management object and the environment in which it exists. But in any case, the risk is seen as a permanent attribute of management. The meaning of the term "risk" is highly variable, but in any case, it is associated with a situation of uncertainty.

The realities of our time dictate for politicians the need of a new level of thinking, which provides an adequate perception of risk and may even use it, as it is an essential component of the analysis of the future. Man and society can eliminate risk, reinterpret it, push it out of consciousness, ignore it, and so on. According to this point of view, risk can be seen as a special method of cognition and management, which acts as a set of ways to make decisions.

A characteristic trend in the historical development of mechanisms for implementing public policy is that in the process of state formation both the institutions of political leadership became larger, and the civil service apparatus, which took care of the implementation of state policy, became larger and hierarchically multilevel. So far, the power of global influence has become quite commensurate with the influence of domestic factors. However, so far the inertia of the old mentality is manifested in the fact that choosing ways to implement public policy developed at the national level, politicians have adapted it only to national specifics. Consideration of the global context relied only on the highest levels of political leadership.

The processes of globalization are driven by the interaction of a system of global, geopolitical, and national interests. The global nature of transnational interests, balances the national interests of different states, in particular, and the world order in general, realizing the concentration of confrontation with global challenges, and the ideals of justice. At the same time, it is not always possible to defend the ideals of justice against the background of harsh realities of geopolitical struggle, the constant process of preferences and balances of interests of individual countries, especially comparing the interests of the old world and emerging countries. 
It is also necessary to pay attention to the fact that under the influence of global processes national interests change, which are formed under the influence of the need for survival of the nation is a system of integrated global structure, which, in turn, forms the appropriate collective consciousness. There are facts of a paradoxical situation when real political and legal decisions are more conducive to the realization of global interests and in some way provoke threats to national interests. Moreover, national and local policymakers are always aware of all possible threats to national interests in their decisions, being influenced by attractive global processes and trends. That is why it is extremely important to control, taking into account, and ensuring national interests in the context of globalization.

In the era of post-industrial society, taking into account the risk of losing the content of national interests is an extremely important component of political activity. Even a patriotic politician in the clash of global and national interests often finds it difficult to defend the interests of his state because of the difficulties of identifying national interests, distinguishing between true and false national interests. This affects both politicians and civil servants, as well as ordinary citizens.

As W. Beck noted: "The national-state world order fragments global inequalities; national equality norms exclude global inequality; comparison of international inequalities reinforces the impossibility of comparison within national frameworks; redefining the irrelevance of large inequalities - all this allows rich and strong states to shift the risk for their decisions to poor countries [10].

Besides, with the intensive development of the global Internet, the opportunities for information cultural aggression by more developed information societies against less developed ones are created, which entails the danger of losing their cultural identity by communities and societies and imposing of consumer guidelines in the business interests of a narrow circle of transnational corporations. Therefore, there are many reasons to exacerbate the problem of preserving national interests under the pressure of global interests. The first is the most annoying, it is associated with notorious corruption, where government officials promote and strengthen the interests of global players for direct or indirect rewards, deliberately putting their interests above patriotism and professional duty.

On the other hand, sometimes, an objective position of a political decision against the background of confrontation of global and national interests is impossible in the absence of identification of national interests, a clear understanding of rational or unfounded national interest.

Modern forecasting techniques must be fully focused on overcoming the destructive impact of globalization on domestic political development. In this regard, it is appropriate to note the need to use the mechanism of alternative studies. In developed countries, global problems are already being replaced by researches of 
alternative civilization and the application of technologies and techniques in the 21st century.

Risk management of public policy in the globalization era should be based, first of all, on the fact that each of the subjects of the political process in the formation and implementation of public policy should resort to forecasting the future conditions of its implementation and its consequences.

It should be noted that the forecasting of political risks is not always unsuccessful due to epistemological difficulties. After all, as evidenced by the extensive practice of political leadership gives evidence that, statesmen are not infrequently under the guise of declaring national interests to realize the interests of others, geopolitical, own, corporate, clean, personal, and even at the cost of harm to national interests.

In other words, the unjustified riskiness of public policy may be not necessarily the result of real prognostic errors of politicians and officials regarding the declared public policy. Real political foresight can be quite successful, but hidden from society, because it is contrary to national interests, in support of the interests of a particular clan or corporation.

At the rate of this feature, these processes can be both cognitive and manipulative, they can be both a process of finding the optimal political decisions for the future and certain concealment of the expected consequences, so to speak, futurological falsification.

Another problem concerns the actual lack of knowledge and systematic work, even in the case of a sincere desire to predict the future conditions and consequences of realization of public policy by the principles of social justice. However, the availability of a system of necessary knowledge is not always a guarantee of the effectiveness of political forecasting of the risks of public policy. There is a mixed relationship between competence in one area or another and predictability. Besides, competence in modern conditions must be combined with modern risk management methodology, using appropriate techniques and technological tools.

Against the background of significant civilizational changes, the development of the information society, and, sometimes, exclusively approving of its perception, is not always taken into account the fact that the consequence of the information revolution is not only positive processes. F. Fukuyama was one of the first to draw attention to several negative phenomena associated with the transition of advanced industrial countries from an industrial to an information society. He called this set of phenomena "the great gap"[9]. First of all, it is the growth of crime, falling birth rates and destabilization of family and family ties, a sharp decline of trust in public institutions and government, weakening the intensity of interpersonal communication, and the stability of relations between citizens, and so on. Political 
forecasting in the information society should be based on the realization that the side effects of actions aimed at implementing this ideal can be destructive processes in the functioning and development of society as a whole, and this may ultimately manifest itself in reducing economic efficiency of society and its defense capabilities, increasing social tensions and the emergence of internal social conflicts, falling public morale, and so on.

That is why today's prognostic methods in the segment of socio-political relations should be aimed at taking into account synergetic, nonlinear metamorphoses, and not only linear and balanced processes. And in this regard in order, to make informed and objective decisions on the formation and implementation of public policy, the urgent issue is the formation of a synergistic mentality in politicians.

Also, an important topic is taking into account the problem of overcoming the ideology of material consumption and the introduction of postmaterial values. The modern world is certainly material, but it is necessary to take into account that the peculiarities of the formation of a certain path aimed at creating another intangible world. A modern politician, who is definitely a statesman and acts exclusively in the interests of society, should think about the future, focusing on post-material issues and innovative technologies.

Recent Ukrainian history reflects a largely one-sided vision of the domestic political elite and focuses only on positive forecasting, idealizing the future, and disregarding possible bifurcations toward undesirable side effects and possible negative consequences or failure to achieve the planned. And with the technological telecommunication development of social relations, the situation is complicated by the fact that the values and knowledge system of the political elite is formed not based on scientific methodology, but under the influence of spontaneous initiatives excited by information technology media, mystifying reality and creating social myths. This situation distorts the perception of reality by the political elite and social myths, gaining additional persuasion, can be perceived by them as the truth of common sense. With such a conjectural mass consciousness that meets the interests of the ruling elite, the real needs of the vast majority of people remain in the shadows. In the information society, enhanced by the role of virtual reality, social illusions capture not only the political elite but also the masses of people, which negatively affects the intellectual component of the reform process.

Ukrainian society civilized connected to the world information technological development, not only fundamentally changes the direction of its development, but also it is forced to solve both current problems and those generated in the past. And abandoning this direction of development is even riskier than stimulating social progress. 
Modern challenges to national security undoubtedly require systematic forecasting on regional integration and disintegration, of European cooperation, etc., systematic development of political analysis, in particular, strategic analysis in key areas of security and social development. Strategic analysis is needed in the context of European and Euro-Atlantic integration, in particular in terms of risks. Ukraine also needs to determine the relationship between its development scenario and global ones, so that Ukraine's place in the world can be assessed in different scenarios. Currently, the strategic forecast is primarily a projective document that contains certain scenarios.

Among other things, the problem of analysis in the public administration system is associated primarily with the existing demand for operational analytics, PR, and speechwriting. For political elites, the most popular is situational analytics, the purpose of which is to respond quickly to events. It is with this approach that PR almost completely replaces politics, including the public, and this, of course, has an extremely negative effect on the level of political analysis, as real analytics are replaced by PR materials.

Given the above, as well as comparing the situation with other countries, we can state that in Ukraine there is no serious demand for strategic analytic. A significant obstacle in Ukraine is the extremely weak level, compared to developed countries, in optimizing the development of the information society, extremely low support for their centers for the study of the future. For example, in the United States, there are hundreds of so-called "thought factories", "brain centers", associations of futurologists, which deal exclusively with futurological issues. Not so long ago, the CIA forecast and analytical material "World in 2020" appeared, which caused a great resonance both in the United States and in the world.

Because of the above, Ukrainian society needs not only state support, but also civil society initiatives to create its futurological infrastructures for analyzing and forecasting scenarios of socio-political development of the state in the information society.

Objective demand has also influenced on the high rate of formation of the relevant special scientific and theoretical base. The number of studies on this issue is growing from year to year, and the volume of works published in Ukraine by foreign and domestic authors on the analysis of public and public policy exceeds that of each of the CIS countries and Central and Eastern Europe. These are several translated and domestic scientific publications on political analysis and forecasting, political consulting, and the theory of political decision-making and programs, which were laid in essence in the late 1990s and early 2000s. necessary methodological principles of political analysis in Ukraine. 
At the same time, a characteristic feature of all works is that they focus mainly on general conceptual issues of formation and development of political analysis and bypass the problems of tool securing, research, and implementation of appropriate analytical methods of preparation, adoption, and implementation of policy decisions. However, the problems of the essential definition of political analytic as a phenomenon and concept, the justification of the whole range of issues related to the theoretical and methodological principles of political analysis as a holistic system of political and managerial scientific knowledge remain unresolved. This is a corresponding limitation and does not give a systematic idea of the essence of political analytic as a modern phenomenon, and also reduces the level of institutionalization of such professional scientific tools in Ukraine, able to truly optimize the process of preparation, adoption, and implementation of political decisions.

Despite the availability of an appropriate methodological framework, there are in some ways anachronisms of the inconsistency of political decisions. In particular, this is manifested in the fact that political decisions in the form of development strategies, concepts are accepted without appropriate prior strategic analysis. There are several hundred such strategies in force in Ukraine today, initiated by various subjects of socio-political relations, which are lacking in the previous analytical process of the study. And this is an extremely serious issue, especially in terms of responsibility and quality. Besides, there is another side of this process - overloading of the political process with an excess of analytical materials. There are dozens and hundreds of analytical materials from a variety of subjects that senior management simply does not have time to study. And the problem is related to the imperfection of the organizational structure of public authorities. Different departments have their analytical services, that often leads to unnecessary competition between different units of one state agency, which causes elementary chaos, the parallelism of analytical units, the imperfection of management in public agencies.

Highlighting the priority of the human mind, it is important to understand that the greater the number of people who are aware of the mind's key role, the better decision making of each person. An abstraction is an indispensable tool that allows the mind to perceive a reality that cannot be definitively understood.

In the development of the analysis of characteristic components of the politics of intelligence, modern political practice shows the dependence of the effectiveness of planning and management on forecasting the level of future socio-political processes. The anticipation of socio-political processes encompasses the theory, methodology, and practice of studying the dynamics and perspectives of the development of various processes and phenomena. Understanding of the whole spectrum of socio-political 
life forms, features of functioning of political institutions and mechanisms, geopolitical institutions depends on the level of such research.

There is an ambiguous relationship of competence in one area or another with the ability to predict. Besides, competence in modern conditions must be combined with the modern methodology of risk management, using appropriate techniques and technological tools. The realities of our time dictate the need for politicians of a new level of thinking, which assumes adequate perception of risk and possibility of its use, as it is an essential component of future analysis.

Ukrainian society needs not only state support, but also civil society initiatives to create its futuristic infrastructure for analyzing and forecasting scenarios of social and political development of the state in an information society environment.

Thus, given the aforementioned and taking into account the essential content of the politics of intelligence, it is appropriate to state the need for orientation in making political decisions on scientifically sound forecasts, because they are one of the guarantees for the foreseeable development of specific events and socio-political processes in general. This is hard to disagree with because in today's conditions, failure to predict means an inability to reform.

\section{References:}

1. Shemshuchenko Yu., Yuschik O. (2007). Politika, pravo, konstitutsiya. Pravo Ukrayini. № 8. S. 6 -8.

2. Popper Karl Raymund. (1992). Otkryitoe obschestvo i ego vragi. Per. s angl. pod obschey red. V.N. Sadovskogo. Perevod vyipolnen s 5-go izd. 1966 g. (reprint 1986 g.). Moskva, Tsentr gumanitarnyih tehnologiy. URL: https://gtmarket.ru/laboratory/basis/3912

3. Taleb Nasim Nikolas. (2017). Chorniy lebid. Pro (ne)ymovirne u realnomu zhitti. Per. z angl. M. Klimchuk. Kiyiv: Nash format. 392 s.

4. Gorbatenko V.P., Butovska I.O. (2005). PolItichne prognozuvannya: navch. posibnik. Kiyia: MAUP. 152 s.

5. Hofshtadter Daglas, Dennet Deniel. (2003). Glaz razuma. Per. s angl. M. Eskinoy. Samara: Izd-skiy dom Bahrah-M. $432 \mathrm{~s}$.

6. BIosfera i noosfera. (2001). Zb. nauk. prats V.I. Vernadskogo. Moskva: Noosfera. S. 159-177.

7. Hayek Fridrih Avgust fon. (2006). Pravo, zakonodatelstvo i svoboda: Sovremennoe ponimanie liberalnyih printsipov spravedlivosti i politiki. Per. s angl B. Pinskera i A. Kustareva; pod red. A. Kuryaeva. Moskva: IRISEN. $644 \mathrm{~s}$.

8. Toffler E. (2001). Metamorfozyi vlasti. Moskva: AST. 699 s.

9. Fukuyama Frensis. (2004). Konets istorii i posledniy chelovek. Moskva: «OOO Izdatelstvo AST: ZAO NPP «Ermak». $588 \mathrm{~s}$.

10. Bek U. (2000). Obschestvo riska. Na puti k drugomu modernu. Per. s nem. V. Sedelniku i N.F.Ftdorovoy. Moskva: Progress-Traditsiya. 384 s. 